joint funding of Amgen, BMS, Celgene, Generic Assays, GSK, Horizon, medac, Mundipharma, Pfizer and Roche.

DOI: 10.1136/annrheumdis-2018-eular.2732

\section{THU0470 NON-CLONAL ELEVATION OF SERUM IMMUNOGLOBULIN FREE LIGHT CHAINS IS PREDICTIVE OF HIP FRACTURE IN BOTH WOMEN AND MEN}

S. Amin, E.J. Atkinson, S.J. Achenbach, A. Dispenzieri, R.A. Kyle, S.V. Rajkumar. MAYO CLINIC, Rochester, USA

Background: Proinflammatory cytokines favour uncoupling of bone turnover and decreased bone density and strength, leading to increased fracture risk. Non-clonal elevation of serum immunoglobulin free light chains (sum of kappa and lambda chains) ( $\sum$ FLC) may be a global marker of generalised immune stimulation, and has been associated with chronic co-morbidities ${ }^{1}$ as well as increased mortality ${ }^{2}$. Objectives: We examined whether elevated $\sum F L C$ is associated with an increased risk for hip fractures in a population-based cohort.

Methods: We studied Olmsted County, Minnesota, USA residents, age $>50$ years, in whom $\sum$ FLC was measured between March 1995 and November 2003 and research authorisation was available. Anyone with a known plasma cell disorder was excluded. Using the Rochester Epidemiology Project, a unique medical records linkage system that allows access to all (inpatient and outpatient) community medical records for Olmsted County residents, we identified all hip fractures that occurred in subjects following their $\sum F L C$ measurement to their last available follow-up or the end of 2015. All available medical records were reviewed by trained nurse abstractors to validate hip fractures identified and to determine their antecedent cause (pathological process [e.g., malignancy], severe trauma [e.g., motor vehicle accidents] and those due to no more than moderate trauma [by convention, equivalent to a fall from standing height or less]) Charlson comorbidity index $(\mathbf{C C l})$ was determined at the time of baseline $\sum$ FLC measurement. We used a Cox proportional hazards model, stratified by sex, adjusting for age, serum creatinine and $\mathrm{CCl}$, to examine whether a $\sum F L C \geq 4.72 \mathrm{mg} / \mathrm{dl}$ (levels previously associated with increased mortality in this population ${ }^{1}$ ) is associated with an increased risk for hip fracture.

Results: We studied 15814 residents [mean age (SD), $64^{10} \mathrm{yrs} ; 8722$ women, 7092 men] of whom 796 (9.1\%) women and 781 (11.0\%) men had a $\sum F L C \geq 4.72 \mathrm{mg} / \mathrm{dl}$. Women and men with an elevated $\sum \mathrm{FLC} \geq 4.72 \mathrm{mg} / \mathrm{dl} \mathrm{had}$ higher CCI [median (IQR) $2(0,4)$ vs $0(0,2)$; same results for both sexes]. We identified 687 women and 255 men with a hip fracture from any cause (628 women and 220 men had a moderate trauma hip fracture), over 112171 person-years (p-y) and 89269 p-y of follow-up, respectively. We found that both women and men with $\sum F L C \geq 4.72 \mathrm{mg} / \mathrm{dl}$ had an increased risk for hip fracture due to any cause: hazard ratio $(\mathrm{HR})[95 \% \mathrm{Cl}] 1.31[1.00,1.73]$ in women, HR $1.97[1.37$, 2.83] in men; as well as for moderate trauma hip fractures: $\operatorname{HR} 1.39[1.05,1.84]$ in women, HR 2.12 [1.46, 3.09] in men.

Conclusions: We found that $\sum F L C \geq 4.72 \mathrm{mg} / \mathrm{dl}$ is associated with an increased risk for hip fracture in both women and men, independent of age and chronic comorbidities. Elevated $\sum$ FLC may be a marker of proinflammatory cytokines detrimental to bone health and warrants further study.

\section{REFERENCES:}

[1] Nakano T, et al. Free Immunoglobulin Light Chain: Its Biology and Implications in Diseases. Clinica Chimica Acta. 2011;412(11-12):843-9.

[2] Dispenzieri A, et al. Use of Nonclonal Serum Immunoglobulin Free Light Chains to Predict Overall Survival in the General Population. Mayo Clinic Proceedings 2012;87(6):517-523.

Acknowledgements: Supported by grant P01 AG04875, R01 CA107476 and R01 AG034676 from the National Institutes of Health, U.S. Public Health Service. Disclosure of Interest: None declared

DOI: 10.1136/annrheumdis-2018-eular.6041

\section{THU0471 RISK FACTORS OF LOW BONE MINERAL DENSITY IN PATIENTS WITH SYSTEMIC SCLEROSIS}

S.V. Monov ${ }^{1}$, D. Monova ${ }^{2}$, M. Stambolova ${ }^{3}$, R. Shumnalieva ${ }^{1} .{ }^{1}$ Department of Rheumatic Diseases, Medical University - Sofia; ${ }^{2}$ Department of Internal Medicine, Medical University - Sofia, Medical Institute; ${ }^{3}$ Department of Internal Medicine, Medical Institute - Ministry of Interior, Sofia, Bulgaria

Background: Systemic sclerosis (SSc) is a multisystem autoimmune disease, characterised by diffuse fibrosis, degenerative changes, and vascular abnormalities in the skin, joints, and internal organs. The effect of systemic sclerosis on bone density is not well understood.

Objectives: The aim of this study is to evaluate the risk factors of low bone mineral density (BMD) and occurrence of fracture and fracture-related mortality in patients with SSc.

Methods: Demographics, disease manifestations of SSc, biological inflammatory parameters, functional disability, scleroderma health assessment questionnaire immunological status, BMD (lumbar spine and femoral neck), risk factors for low $\mathrm{BMD}$, fractures, and fracture-related mortality were collected in patients with SSc. BMD was measured by using a dual-energy $X$-ray absorptiometry in lumbar spine (L1-L4) and femoral neck. Fisher's Exact and Student's t-tests were used to evaluate differences between women with and without low BMD. Logistic regression was used for multivariate analysis.

Results: Forty eight consecutive unselected SSc women were approached. The mean age of women was $48,32 \pm 15,56$ years, the mean disease duration was $10,12 \pm 4,78$ years, Twenty-nine women $(60,42 \%)$ had low BMD, of those 11 $(37,93 \%)$ had osteoporosis, mean BMD in lumbar spine was $-2,86 \pm 0,38$ and in femoral neck was $-2,22 \pm 0,26$. Twenty three $(47,92 \%)$ women with SSc were postmenopausal. In correlation analysis and in multiple regression models, there were correlations between BMD and longer duration of SSc $(p<0,01)$, family his tory of osteoporosis $(p<0.05)$, age $(p<0,01)$, menopause $(p<0,01)$, low body mass index $(p<0,02)$, presence of internal organ involvement $(p<0,05)$, malabsorption syndrome $(p<0,05)$, joint involvement (severe joint pain and erosive arthropathy) $(p<0,05)$, and immunological status (positivity of anti-DNA topoisomerase I antibodies) $(p<0,05) .4$ women $(4 / 29)$ with low BMD had a fracture, compared to 2 without low BMD. Fracture-related mortality did not occur in any patients.

Conclusions: Our data suggest that women with SSc are at risk of low BMD and fracture, especially when other risk factors for osteoporosis are present. A number of clinically relevant factors (longer duration of SSc, presence of internal organ involvement, joint involvement, immunological status) are associated with low BMD.

Disclosure of Interest: None declared

DOI: 10.1136/annrheumdis-2018-eular.1886

\section{THU0472 FACTORS ASSOCIATED WITH READINESS FOR ADOPTING OSTEOPOROSIS TREATMENT CHANGE}

M.I. Danila ${ }^{1}$, E.J. Rahn ${ }^{1}$, A.S. Mudano ${ }^{1}$, R.C. Outman ${ }^{1}$, P. Li ${ }^{1}$, D.T. Redden ${ }^{1}$, F. A. Anderson ${ }^{2}$, S.L. Greenspan ${ }^{3}$, A.Z. LaCroix ${ }^{4}$, J.W. Nieves ${ }^{5}$, S.L. Silverman ${ }^{6}$, E. S. Siris ${ }^{7}$, N.B. Watts ${ }^{8}$, S. Ladores ${ }^{1}$, K.M. Meneses ${ }^{1}$, J.R. Curtis ${ }^{1}$, K.G. Saag ${ }^{1}$ ${ }^{1}$ University of Alabama at Birmingham, Birmingham; ${ }^{2}$ University of Massachusetts Medical School, Worcester, ${ }^{3}$ University of Pittsburgh, Pittsburgh; ${ }^{4}$ Group Health Cooperative, Seattle; ${ }^{5}$ Helen Hayes Hospital, West Haverstraw, ${ }^{6}$ Cedars-Sinai Medical Center, Los Angeles; ${ }^{7}$ Columbia University Medical Center, New York; ${ }^{8}$ Mercy Health Osteoporosis and Bone Health Services, Cincinnati, USA

Background: Understanding factors associated with the readiness for adopting osteoporosis treatment change may inform the design of behavioural interventions to improve osteoporosis treatment uptake in women at high risk for fracture. Objectives: To examine the factors associated with the readiness for adopting osteoporosis treament change among US women with prior fractures.

Methods: US women in the Global Longitudinal Study of Osteoporosis (GLOW) with prior self-reported fractures who were not currently using osteoporosis therapy were eligible to participate in the Activating Patients at Risk for OsteoPOroSis (APROPOS) Study. Participants' readiness for behaviour change was assessed using a modified form of the Weinstein Precaution Adoption Process Model (PAPM). We defined pre-contemplative participants as those who self-classified in the unaware and unengaged stages of PAPM. Contemplative participants were defined by the undecided, decided not to act, and decided to act stages of PAPM. Bivariate tests and stepwise multivariable logistic regression evaluated the following factors associated with these two levels of readiness for behaviour change: sociodemographic characteristics, health literacy, self-reported history of depression and dementia, previous treatment for osteoporosis, whether participants had been told they had osteoporosis/osteopenia, and whether they had concerns about osteoporosis.

Results: A total of 2684 women were enrolled in APROPOS. Participants were $95 \%$ Caucasian, with a mean (SD) age $74.9(8.0)$ years and $77 \%$ had some college education. Overall, $25 \%(n=544)$ self-classified in the contemplative stage of behaviour change. Compared to women who self-classified as pre-contemplative, contemplative women were more likely to be concerned about osteoporosis (adjusted OR $[\mathrm{aOR}]=3.2,95 \% \mathrm{Cl} 2.3-4.4$ ) and to report prior osteoporosis treatment (aOR 4.3, 95\% Cl 3.1-6.0). Participants who were told they had osteoporosis had a 12.4 fold odds to be in the contemplative group (95\% $\mathrm{Cl} 8.5-18.1$ ), while those who were told they had osteopenia had 4.1 fold odds to be in the contemplative group $(95 \% \mathrm{Cl} 2.9-5.9)$. 


\begin{tabular}{|c|c|c|c|c|c|c|c|c|c|c|}
\hline & Age $>75$ & $\begin{array}{c}\text { Sex } M \text { vs } \\
F\end{array}$ & Residence & $\begin{array}{l}\text { Hepatic } \\
\text { Disease }\end{array}$ & CRF & OCFA & Dementia & $\mathrm{CHF}$ & $\begin{array}{l}\text { Diabetes } \\
\text { mellitus }\end{array}$ & $\begin{array}{c}\text { Charlson i. } \\
>2\end{array}$ \\
\hline $\begin{array}{l}\text { HR } \\
\text { IC } \\
95 \%\end{array}$ & $\begin{array}{c}1,05 \\
(1.04- \\
1.06)\end{array}$ & $\begin{array}{c}1,32 \\
(1.21-1.44)\end{array}$ & $\begin{array}{c}1,48 \\
(1.36-1.60)\end{array}$ & $\begin{array}{c}3,25 \\
(2.17-4.86)\end{array}$ & $\begin{array}{c}1,87 \\
(1.60- \\
2.18)\end{array}$ & $\begin{array}{c}1,46 \\
(1.30- \\
1.64)\end{array}$ & $\begin{array}{c}1,46 \\
(1.30-1.62)\end{array}$ & $\begin{array}{c}2,50 \\
(2.07- \\
3.00)\end{array}$ & $\begin{array}{c}1,11 \\
(1.02-1.22)\end{array}$ & $\begin{array}{c}1,98 \\
(1.73-2.26)\end{array}$ \\
\hline
\end{tabular}

Conclusions: Among women with high risk of future fracture, having been told by a health care provider that they had osteoporosis/osteopenia was independently associated with considering taking medications for osteoporosis. Our results suggest that in considering osteoporosis intervention design efficiency and effectiveness, women's recognition of a diagnosis of osteoporosis/osteopenia are critical components to be considered when attempting to influence stage of behaviour transitions.

Disclosure of Interest: M. I. Danila: None declared, E. Rahn: None declared, A. Mudano: None declared, R. Outman: None declared, P. Li: None declared, D. Redden: None declared, F. Anderson Grant/research support from: Portola, Consultant for: Millennium Pharmaceuticals, S. Greenspan Grant/research support from: Amgen, Lilly, Consultant for: Merck, A. LaCroix Consultant for: Amgen, Pfizer, Sermonix, J. Nieves: None declared, S. Silverman Grant/research support from: Amgen, Lilly, Consultant for: Amgen, Speakers bureau: Amgen, Lilly, E. Siris Consultant for: Amgen, Radius, N. Watts Shareholder of: OsteoDynamics, Grant/ research support from: Shire, Consultant for: AbbVie, Amgen, Janssen, Merck, Radius, Sanofi, Paid instructor for: Amgen, Shire, S. Ladores: None declared, K. Meneses: None declared, J. Curtis Grant/research support from: Amgen, Consultant for: Amgen, K. Saag Grant/research support from: Amgen, Lilly, Merck, Consultant for: Amgen, Lilly, Merck

DOI: 10.1136/annrheumdis-2018-eular.4802

\section{THU0473 TREND OF MORTALITY AFTER OSTEOPOROTIC HIP FRACTURE IN A PERIOD OF 17 YEARS}

R. Mazzucchelli' ${ }^{1}$ O. Guzón-lllescas ${ }^{2}$, E. Pérez-Fernandez ${ }^{2}$, M. Peña ${ }^{2}$, J. Quirós ${ }^{2}$, N. Crespí_Villarías ${ }^{3}$, A. García-Vadillo ${ }^{4}{ }^{1}$ Rheumatology; ${ }^{2}$ Hospital U. Función Alcorcón; ${ }^{3}$ C.S La Rivota, Alcorcón; ${ }^{4}$ H. U. La Princesa, Madrid, Spain

Background: It is known that the mortality after a hip fracture is increased with respect to the general population. However, the trend of mortality is a controversial issue.

Objectives: The objective of this study is to analyse the incidence, trend and factors associated with mortality in patients with osteoporotic hip fracture.

Methods: This is a retrospective cohort study using the Minimum Basic Data Set (MBDS) of our hospital that collects a minimum data set at hospital discharge. We identified patients older than 45 years who suffered an osteoporotic hip fracture during the period from 1999 to 2015. (3992 hip fractures). The demographic data and comorbidities were obtained from the exploitation of the MBDS and the Income Nursing Assessment Form (subgroup of 810 patients). The identification of the deceased was obtained by consulting the MBDS and the INDEF (National Death Index facilitated by the Ministry of Health). A survival analysis was performed (regression of Cox and Kaplan-Meier). The incidence rate, standardised mortality index (SMI) was calculated with respect to the mortality of the general population of Madrid (mortality data of the general population obtained INE), trend (Poisson regression) and risk (Hazard Ratio) for the different clinical and demographic variables.

Results: The cumulative incidence of mortality was $72.69 \%$ in the study period. The crude mortality rate at $1,3,6$ months and 1 and 3 years was $9.2 \%, 17.4 \%$, $24.6 \%, 33 \%$ and $56 \%$, respectively. In men it was $13.7 \%, 25 \%, 32.7 \%, 43.3 \%$ and $65.6 \%$ and in women $7.9 \%, 15.7 \%, 22.3 \%, 30 \%, 53.2 \%$. The median overall survival was 886 days (95\% Cl: 836-951), with 576 for men and 998 for women. A statistically significant reduction in median survival was observed throughout the study period. The IME was 8.3 (95\% Cl: 7.98-8.59); (similar values in men and women). The clinical-demographic variables that showed a statistically significant association with mortality are shown in the following table 1 (HR and p-value): Other variables that showed statistical association were: presence of auditory and visual alterations, incontinence (urinary and faecal) and the total score on the Norton scale and the Downton scale.

Conclusions: We found an increase in mortality (or decrease in median survival) of patients with hip fracture during the last 17 years. An oncrease in mortality has been observed in patients with hip fracture related to age, male sex, diabetes, hepatic disease and living in a nursing home.

Disclosure of Interest: None declared

DOI: 10.1136/annrheumdis-2018-eular.1512

\section{THU0474}

\section{UTILISATION OF ANTI-OSTEOPOROTIC DRUGS IN REAL-WORLD DATA: AN ANALYSIS OF PERSISTENCE TO THERAPY AND RISK OF FRACTURE}

V. Orlando ${ }^{1}$, V.M. Monettii ${ }^{1}$, F. Guerriero ${ }^{1}$, A. Moretti ${ }^{2}$, V. Russo ${ }^{1}$, A. Piscitelli ${ }^{1}$ G. Iolascon' ${ }^{2}$, E. Menditto ${ }^{1} .{ }^{1}$ CIRFF Center of Pharmacoeconomics, University of Naples Federico II; ${ }^{2}$ Department of Medical and Surgical Specialties and Dentistry, University of Campania "Luigi Vanvitelli", Naples, Italy

Background: Osteoporosis is a chronic progressive disease characterised by low bone mass and deterioration of bone structure, leading to an increate risk of fractures. It is a major public health problem, affecting hundreds of millions of people worldwide. The primary aim of pharmaceutical therapy is to reduce the risk of osteoporotic fractures. However, long-term adherence to therapy is requie for optimal therapeutic benefit for patients with osteoporosis. Poor adherence is considered to be one primary reason for suboptimal clinical benefit.

Objectives: The aim of this study was to investigate the determinants of non-persistence and impact of persistence on the risk of fractures by using administrative databases.

Methods: We conducted a retrospective cohort study using administrative data from four local health authorities in the Abruzzo Region (Central Italy), which comprise about 900000 inhabitants (68\% of the overall regional population). The final cohort consisted of a total of 7862 patients, aged $\geq 60$ years, identified through records of filled prescriptions for an antiosteoporotic drug between January 1, 2006 to December 31,2006 . The primary outcome of this study was persistence at one year. Persistence was defined as the length of time (in days) from the date of the index prescription to the date of discontinuation therapy.

Results: Kaplan - Meier analysis showed that 3733 patients (47.5\%) were persistent with antiosteoporotic drugs after 1 year. An adjusted analysis showed that there is a big difference in persistence between women and men: women are more likely to be non-persistent than men (HR:1.94). Switcher patients were more likely to be non-persistent (HR:1.22). The odds of fracture were significantly higher for patients with previous fractures in comparison with those without previous fractures [OR, 1.70, $(95 \% \mathrm{Cl}, 1.12-2.59)]$ (table 1)

Table 1 Logistic regression model: impact of persistence and other factors on the risk fracture

\begin{tabular}{|c|c|c|c|c|}
\hline Characteristics & Unadjusted $\mathrm{OR}(95 \% \mathrm{CI})$ & $p$-value & Adjusted OR $(95 \% \mathrm{CI})$ & $p$-value \\
\hline \multicolumn{5}{|l|}{ Gender } \\
\hline Male & Reference & & & \\
\hline Female & $1.31(0.93-1.85)$ & 0.119 & $1.28(0.91-1.82)$ & 0.159 \\
\hline \multicolumn{5}{|l|}{ Age } \\
\hline $60-69$ & Reference & & & \\
\hline $70-79$ & $1.54(1.14-2.06)$ & 0.005 & $1.52(1.13-2.06)$ & 0.006 \\
\hline$\geq 80$ & $2.56(1.89-3.45)$ & $<0.001$ & $2.49(1.83-3.39)$ & $<0.001$ \\
\hline \multicolumn{5}{|l|}{ Previous fractures } \\
\hline No & Reference & & & \\
\hline Yes & $1.71(1.58-1.84)$ & $<0.01$ & $1.70(1.12-2.59)$ & 0.013 \\
\hline \multicolumn{5}{|l|}{ Persistence } \\
\hline No & Reference & & & \\
\hline Yes & $0.78(0.63-0.97)$ & 0.022 & $0.79(0.63-0.97)$ & 0.026 \\
\hline \multicolumn{5}{|l|}{ ACCI } \\
\hline Zero score [0] & Reference & & & \\
\hline Mild score [1-4] & $0.86(0.32-2.36)$ & 0.772 & $1.35(0.49-3.78)$ & 0.562 \\
\hline Severe score $[\geq 5]$ & $1.50(1.06-2.12)$ & 0.022 & $1.33(0.94-1.90)$ & 0.112 \\
\hline
\end{tabular}

Conclusions: Persistence with antiosteoporotic drugs is a significant predictor of incurring a fracture. For these reason, improving osteoporosis treatment compliance and persistence represents one of a major challenge for the future.

\section{REFERENCES:}

[1] Casula M, Filippi A, Flacco E, Gambera M, Manzoli L, Menditto E, Orlando V, Piccinelli R, Tragni E, Catapano A. Assessment and potential determinats of compliance and persistence to anti-osteoporosis therapy in Italy. Am J Manag Care 2014;20(5):e138-e145.

[2] Iolascon G, Gimigliano F, Orlando V, Capaldo A, Di Somma C, Menditto E. Osteoporosis drugs in real-world clinical practice: an analysis of persistence. Aging Clin Exp Res 2013 Oct;25 Suppl 1:S137-41. 